\title{
Interaction Parameters of Surfactant Mixtures by Inverse Gas Chromatography
}

\author{
Eleuterio Luis Arancibia ${ }^{1}$, Pablo C. Schulz ${ }^{2}$ and Susana M. Bardavid ${ }^{1}$ \\ ${ }^{1}$ INQUINOA - CONICET- FACET - UNT- Tucumán, \\ ${ }^{2}$ INQUISUR - CONICET -FQ -UNS - Bahia Blanca, \\ Argentina
}

\section{Introduction}

Inverse Gas Chromatography (IGC) is an accurate and versatile technique for determining a variety of properties of different materials (Voelkel, A. et al., 2009). IGC has also shown to be an effective way to determine thermodynamic properties in polymer materials, especially to obtain Flory-Huggins interaction parameters, which can be used to calculate energy densities interaction $\left(B_{23}\right)$ in polymer-polymer systems. These parameters have been employed for evaluating thermodynamic miscibility in polymer mixtures (Deshpande, et al., 1974; Lezcano, et al., 1995).

The major difficulty in those determinations relies on the dependence of the parameters obtained on the solvents used as probe solutes. In spite of the fact that the relations obtained from interaction studies through IGC can be applied to miscible systems, the studies in systems that present partial or total inmiscibility have been made in several polymer systems (Du, et al., 1999; Zhikuan, C. \& Walsh, D.J., 1983).

The relation from which $B_{23}$ data are obtained describes a ternary system as a simple balance of the corresponding binary ones. It is well known their small contribution to this relation (Etxeberria, et al., 1994, 1995). Besides, the interaction parameter is several orders of magnitude smaller than that of the retention property determined by IGC. An attempt to reduce the uncertainty in the $\mathrm{B}_{23}$ parameter has led to establish an adequate selection of probe solutes (Etxeberria et al., 2000). These authors have also demonstrated that the results obtained from IGC as well as from static technique are similar when $\mathrm{CO}_{2}$ is used as a probe solute.

As indicated by several authors, the polymer-polymer interaction parameter determined by IGC shows a clear dependence on the solvent used as a probe. In order to solve this problem, different methods have been proposed (El-Hibri, et al., 1988; Etxeberria, et al., 1994, 2000; Farooque, \& Deshpande, 1992; Huang, 2003a, 2003b; Prolongo, et al., 1989; Zhao, \& Choi, 2001).

Farooque and Deshpande's proposed methodology (Farooque, \& Deshpande, 1992) has allowed the determination of reliable polymer-polymer interaction parameters by IGC. Huang's later proposal (Huang, 2003a, 2003b) based on a methodology similar to the latest 
has been applied to several systems and has been compared with the previous methodology using retention data in polymer materials (Benabdelghani, et al., 2006).

In the case of liquid crystals, they have been thoroughly investigated as stationary phases by gas liquid chromatography (GLC) from an analytical point of view (Janini, et al., 1975; Janini, et al., 1980; Martire, et al., 1968). They have also been used in studies of solution thermodynamic, by inverse gas chromatography (IGC) of solutes in liquid crystals (CL) and in polymer liquid crystals (CLP) at infinite dilution (Chow \& Martire, 1971; Romannsky \& Guillet, 1994; Romannsky, et al., 1994; Shillcock \& Price, 2004).

Huang et al. (Huang, et al., 2007) has studied the solution properties of a series of organic solutes in liquid crystals using IGC through activity coefficients and free energy transference of solute between mesophases and an isotropic phase. In these systems, constant values of free energy of transference have been obtained applying lattice's model of polymer solutions (Flory, 1953) and Flory's treatment of liquid crystals (Flory, 1956; Flory, 1984). The treatment of the data obtained via IGC in order to get thermodynamic properties using Flory's classic model has been more frequently applied to mesophases than to Flory's liquid crystal model. In the derivation of this model, the expression that corresponds to the non-combinatory contribution has been discarded (Abe \& Flory, 1978; Flory \& Abe, 1978); thus, the interaction parameter $\chi_{1,2}$ between probe solute and stationary phase, that represents the energy exchange of interactions, has not been included. This might be one of the reasons because the interaction parameter is obtained preferably by Flory's classic model of polymers.

Since the probe solute is at near infinite dilution, the order of the liquid crystal phase is not destroyed by the probe solute inclusion. The accessibility of the probe molecules in a mesophase could be limited by its ordering. This means that the main interaction occurs with the hydrocarbon chains of the bilayers and the interactions are mainly of dispersive character. We can estimate the degree of interaction solute - stationary phase by Flory Huggins' interaction parameter obtained by IGC using surfactants as stationary phase.

The amphiphilic molecular structure of surfactants has a significant influence in the crystals phase structure. The packing of the surfactants is produced so that the liphophilic groups of the different molecules are associated with every lipophilic region. Their hydrophilic groups are equally associated within the polar region. In this way, they form the so called bilayers which are usually formed in crystals of simple or double hydrocarbon chain surfactants. Some surfactant crystals do not melt in a liquid phase directly but go through anhydrous liquid crystal phases (thermotropic liquid crystals) before reaching the isotropic liquid state. The liquid crystals of anhydrous surfactants are thermotropic since they result only from the temperature increase on anhydrous crystals (Laughlin, 1994).

This chapter is part of a series of works done in this laboratory, where several surfactant properties such as solubility parameters, surfactant-surfactant interaction parameters in several systems made up by cationic surfactants of different hydrocarbon length chain have been determined by IGC (Bardavid, et al., 2003, 2007; Proverbio, 2003; Schaefer, 2008).

The vast majority of the works related to surfactant mixtures have been made at low concentration in aqueous solutions. The mixing of different types of surfactants gives rise to synergies that provide the opportunity to optimize product performance. For surfactant mixtures the characteristic phenomena are the formation of mixed monolayers at the 
interface and mixed micelles in the bulk solution. In such solutions, adsorption behaviour, aggregates' microstructure, and rheological properties can be manipulated to tailor the properties of the different products.

In ionic anhydrous surfactant systems, the structures of liquid crystals and crystals are based on the simultaneous fulfillment of two kinds of interactions: van der Waals interactions in the hydrocarbon bilayers and the electrostatic interactions in the ionic bilayers. Sometimes, steric interactions can appear in the hydrocarbon bilayers, and polar interactions or hydrogen bonds can appear in the ionic bilayers (Schulz et al., 1996). A combination of these interactions can be especially disclosed in mixed amphiphiles systems, and their study can lead to a better understanding of their influence in the formation and stability of the microstructures mentioned above.

The cationic surfactants mixed systems are becoming more important and in the future additional complex formulation a and multiple technological products will be required. The extension to a thermodynamic approximation of multicomponents including additional phenomena like solubility will allow the establishment of more complex systems (Holland \& Rubingh, 1990). There is not much information about studies of cationic surfactant mixture phases (Varade, et al., 2008), or the miscibility of pure surfactant mixtures (Bardavid, et al., $2007,2010)$ that allow resemblance to the behaviour of surfactant mixtures interactions in mixed micelles.

In this chapter we present the results obtained from the study of miscibility of cationic surfactant mixtures of three systems made up by mixtures of surfactants of equal polar head and different hydrocarbon chains by determining surfactant-surfactant interaction parameters through IGC. The implementation of this technique has also allowed us to analyze the use of two methodologies of measurement in order to obtain the parameter $B_{23}$ for cationic surfactants and to contrast them with the ones obtained in polymeric materials. With this work we hope to enlarge the information about the behaviour of pure surfactant mixtures, and analyze the non-ideality degree in the mixtures and its possible causes.

\section{Experimental}

\subsection{Materials}

Dodecylpyridinium chloride (DPC), Hexadecylpyridinium bromide (Cetylpyridinium bromide (CPB)), Dodecyltrimethylammonium bromide (DTAB), Octadecyl trimethylammonium bromide (OTAB), (Aldrich, analytical grade, USA) Didodecyldimethylammonium bromide (DDAB) and Dioctadecyldimethylammonium bromide (DODAB) (Sigma, analytical grade, USA) were used as received. All probe solutes were chromatographic quality or reagent grade and were used without further purification.

\subsection{Differential Scanning Calorimetry (DSC)}

DSC was performed on a Perkin Elmer DSC 6 calorimeter, between 293 and 523 K, with a scanning rate of 10 degree $\mathrm{min}^{-1}$ and using samples of 5-10 mg for pure surfactants and 10$15 \mathrm{mg}$ for materials collected over chromatography support. The instrument was calibrated with indium. 


\subsection{Inverse Gas Chromatography (IGC)}

Pure surfactants and their mixtures were used as stationary phase and deposited on Chromosorb W or G, AW, 60/80, which was employed as solid support. The column filler was prepared using methanol as a solvent in a rotary evaporator under a flow of dry nitrogen and was kept in a dry atmosphere before filling the columns (stainless steel pipes). The column was loaded and conditioned for $1 \mathrm{~h}$ at $363 \mathrm{~K}$ under a flow of carrier gas. The amount of stationary phase on the support was determined by calcinations of about one gram of material. The data employed in the specific retention volume computation were obtained by using a column $100 \mathrm{~cm}$ long, 1/4 inch external diameter, and the packing characteristics are included in Table 1.

\begin{tabular}{|c|c|c|c|}
\hline \multicolumn{4}{|c|}{ System DDAB (2) - DODAB (3) } \\
\hline \multirow[t]{2}{*}{ Stationary phase } & Mass packing & Loading $(\mathrm{w} / \mathrm{w})$ & Weight fraction \\
\hline & $(\mathrm{g})$ & $(\%)$ & $\left(w_{2}\right)$ \\
\hline DDAB (2) + DODAB (3) & 7.2653 & 9.12 & 0.0000 \\
\hline DDAB (2) + DODAB (3) & 7.6432 & 9.22 & 0.1643 \\
\hline DDAB (2) + DODAB (3) & 7.8634 & 9.23 & 0.3281 \\
\hline DDAB (2) + DODAB (3) & 7.0268 & 9.53 & 0.5037 \\
\hline $\operatorname{DDAB}(2)+$ DODAB (3) & 7.0906 & 9.60 & 0.7325 \\
\hline DDAB (2) + DODAB (3) & 7.8856 & 9.11 & 1.0000 \\
\hline \multicolumn{4}{|l|}{ System DPC (2) - CPB (3) } \\
\hline \multirow[t]{2}{*}{ Stationary phase } & Mass packing & Loading $(\mathrm{w} / \mathrm{w})$ & Weight fraction \\
\hline & $(g)$ & $(\%)$ & $\left(\mathrm{w}_{2}\right)$ \\
\hline $\mathrm{DPC}(2)+\mathrm{CPB}(3)$ & 13.2318 & 7.44 & 0.0000 \\
\hline $\mathrm{DPC}(2)+\mathrm{CPB}(3)$ & 12.9175 & 7.82 & 0.1598 \\
\hline $\mathrm{DPC}(2)+\mathrm{CPB}(3)$ & 12.9056 & 7.72 & 0.3461 \\
\hline $\mathrm{DPC}(2)+\mathrm{CPB}(3)$ & 12.6945 & 7.42 & 0.5409 \\
\hline $\mathrm{DPC}(2)+\mathrm{CPB}(3)$ & 12.9240 & 7.39 & 0.7590 \\
\hline $\mathrm{DPC}(2)+\mathrm{CPB}(3)$ & 12.5835 & 7.41 & 1.0000 \\
\hline \multicolumn{4}{|c|}{ System DTAB (2) - OTAB (3) } \\
\hline \multirow[t]{2}{*}{ Stationary phase } & Mass packing & Loading $(w / w)$ & Weight fraction \\
\hline & $(\mathrm{g})$ & $(\%)$ & $\left(\mathrm{w}_{2}\right)$ \\
\hline DTAB (2) + OTAB (3) & 7.2301 & 10.09 & 0.0000 \\
\hline DTAB (2) + OTAB (3) & 6.7947 & 10.04 & 0.1102 \\
\hline DTAB (2) + OTAB (3) & 7.4240 & 10.02 & 0.3652 \\
\hline DTAB (2) + OTAB (3) & 7.3281 & 9.99 & 0.5963 \\
\hline DTAB (2) + OTAB (3) & 7.2392 & 11.64 & 0.8331 \\
\hline DTAB (2) + OTAB (3) & 7.0746 & 10.03 & 1.0000 \\
\hline
\end{tabular}

Table 1. Column loading data and the weight fraction at the different mixtures.

The retention time measurement for each solute was performed with a Hewlet Packard, HP 6890 series, GC System, equipped with a flame ionization detector (FID). Column temperature was measured in a range between 343.1 and $403.1 \mathrm{~K}$ with an Iron-Constantan thermocouple 
placed in the direct environment of the column. The temperature stability during experiments was $\pm 0.2 \mathrm{~K}$. The employed solutes were n-hexane, n-heptane, n-octane, n-nonane, cyclohexane, methylcyclohexane, benzene, toluene, ethyl acetate, dichloromethane, trichloromethane and carbon tetrachloride. Nitrogen was used as carrier gas.

Flow rates were measured at the beginning of each experiment with an air-jacketed soap film flowmeter placed at the outlet of the detector. Inlet pressures were measured with a micrometry syringe (trough the injector septum) which was connected to an open branch mercury manometer. To ensure that the results were independent of sample size and flow rate and those measurements were being made at infinite dilution the usual checks were made (Conder \& Young, 1978). Solutes were injected with $10 \mu \mathrm{l}$ Hamilton syringes, as steam in equilibrium with pure liquid. For all the solutes and for all the range of stationary phase concentrations the peaks were symmetric. The injector was kept at $423 \mathrm{~K}$ and the detector at $453 \mathrm{~K}$.

Retention times $\left(t_{R}\right)$ were measured with a Chem Station system and the retention specific volumes $\left(\mathrm{V}_{\mathrm{g}}\right)$ were calculated with the following relationship (Conder \& Young, 1978):

$$
V_{g}^{0}=j\left(F_{f} / w\right)\left(273.15 / T_{f}\right)\left(t_{R}-t_{0}\right)\left(\left(p_{0}-p_{w}\right) / p_{0}\right)
$$

where $\mathrm{j}$ is the James-Martin compressibility correction factor, $\mathrm{p}_{0}$ represents the outlet column pressure, $F_{f}$ is the flow rate measured at pressure $p_{0}$ and temperature $T_{f}, w$ is the mass of the stationary phase into the column and $p_{w}$ is the water vapour pressure at $T_{f} ; t_{0}$ is the dead time, which was measured by using the methane peak obtained with the FID.

\section{Data reduction}

Specific retention volumes were fitted to the equation (Conder \& Young, 1978):

$$
\ln V_{g}^{0}=-\Delta H_{s}^{0} / R T+\text { cons } \tan t
$$

where $\Delta \mathrm{H}^{\circ}$ is the sorption heat. The values obtained for $\Delta \mathrm{H}^{\circ}$, as well as their respective standard deviations, were calculated using Marquartd-Levenberg's algorithm (Marquartd, 1963) and can be seen in Table 2. Values of standard deviations in $\Delta H_{s}$ smaller than $1.5 \%$ are obtained in the regression of specific retention values vs. $1 / \mathrm{T}$, although most of the values were near $1.0 \%$.

The meaning of $\Delta \mathrm{H}^{\circ}$ s depends on the physical state of the stationary phase. For a solid, $\Delta \mathrm{H}^{\circ}{ }_{\mathrm{s}}$ correspond to the molar adsorption enthalpy. For the liquid mesophase, it was assumed that the solute is dissolved in the stationary phase so $\Delta \mathrm{H}^{\circ}$ s corresponds to the molar solution enthalpy.

The average per cent error values $\Delta \mathrm{H}^{\circ}{ }_{\mathrm{s}}$ for DDDAB is $0.88 \%$, and $0.74 \%$ for DODAB. For the DPB-CPB systems the average error \% is $0.79 \%$ for DPC and for CPB is $1.20 \%$. Finally, for the mixed systems DTAB-OTAB the average error in $\Delta \mathrm{H}^{\circ}$ s values is generally bigger than the previous ones and from the calculated values we get a value of $1.38 \%$ for the average error in DTAB and of $1.10 \%$ for the values in OTAB. 


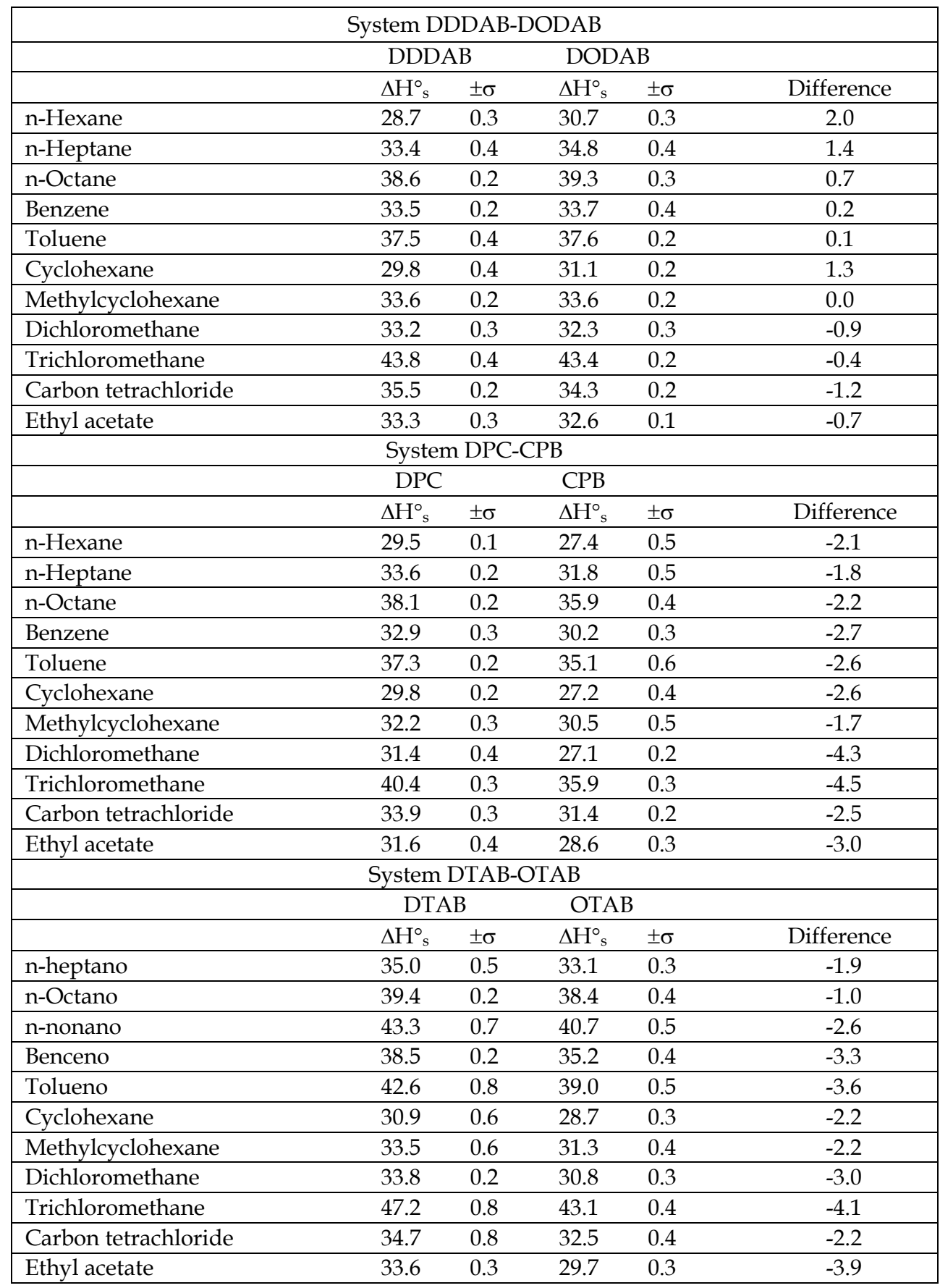

Table 2. Solution heat $\left(\mathrm{kJ} \cdot \mathrm{mol}^{-1}\right)$ and standard deviations for of the surfactant mixtures. 
Activity coefficients at infinite dilution in terms of mole fraction were obtained by the following expression (Price et al., 2002):

$$
\ln \gamma_{i}^{\infty}=\ln \frac{273.15 R}{V_{g}^{0} p_{1}^{0} M_{2}}-\frac{p_{1}^{0}\left(B_{11}-V_{1}\right)}{R T}
$$

where $\mathrm{M}_{2}$ stands for molar mass of surfactant, $\mathrm{p}_{1}{ }^{0}, \mathrm{~V}_{1}$ stands for vapour pressure and molar volume of pure solute. $B_{11}$ is the second virial coefficient for solute-solute interactions.

Patterson (Patterson et al., 1971) suggested using the weight fraction, w, in which case equation (3) may be replaced by expression:

$$
\ln \Omega_{i}^{\infty}=\ln \frac{273.15 R}{V_{g}^{0} p_{1}^{0} M_{1}}-\frac{p_{1}^{0}\left(B_{11}-V_{1}\right)}{R T}
$$

where $\mathrm{M}_{1}$ is the molar mass of the solute.

The Flory-Huggins theory of non-athermal solutions gives:

$$
\ln a_{1}=\left(\ln a_{1}\right)_{\text {comb. }}+\left(\ln a_{1}\right)_{\text {noncomb. }}=\left(\ln \phi_{1}+\left(1-\frac{1}{r}\right) \phi_{i}\right)+\chi \phi_{i}^{2}
$$

where the volume fraction, $\phi$, is defined in terms of the specific volumes.

For the limiting case in which $\phi_{1}$ tends to unity, using the equations (4) and (5), the probe solute-surfactant Flory-Huggins interaction parameter, $\chi_{1 \text { i }}$, can be calculated from the specific retention volumes, $\mathrm{V}_{\mathrm{g}}^{\mathrm{g}}$, by the expression (Conder \& Young, 1978; Deshpande, et al., 1974):

$$
\chi_{1 i}^{\infty}=\ln \left(\frac{273.15 R v_{i}}{V_{g}^{0} p_{1}^{0} V_{1}}\right)-\left(\frac{p_{1}^{0}\left(B_{11}-V_{1}\right)}{R T}\right)-\left(1-\frac{V_{1}}{V_{i}}\right)
$$

where $v_{i}$ stands for the specific volume of the surfactant experimentally measured in the laboratory.

The vapour pressures were computed using Antoine equations and the coefficients were taken from Riddick, Bunger and Sakano (Riddick, et al., 1986). The solute densities at different temperatures were estimated from Dreisbach's compilation (Dreisbach, 1955). The second virial coefficient of the solutes was calculated by Tsonopoulos's correlation using critical constants tabulated in Reid et al. (Reid et al., 1986).

When the stationary phase is a surfactant mixture, Equation (7) allows to determine the ternary probe solute (1)-surfactant (2)-surfactant (3) interaction parameter, $\chi_{1(23) \text {, assuming }}$ an additive specific volume for the surfactant mixture, $v_{m}=w_{2} v_{2}+w_{3} v_{3}$ where $w_{i}$ is the weight fraction of surfactant $i$ in the mixture (Deshpande, et al., 1974). 


$$
\chi_{1(23)}^{\infty}=\ln \left(\frac{273.15 R\left(w_{2} v_{2}+w_{3} v_{3}\right)}{V_{g}^{0} p_{1}^{0} V_{1}}\right)-\left(\frac{p_{1}^{0}\left(B_{11}-V_{1}\right)}{R T}\right)-\left(\phi_{2}\left(1-\frac{V_{1}}{V_{2}}\right)+\phi_{3}\left(1-\frac{V_{1}}{V_{3}}\right)\right)
$$

where $\phi_{\mathrm{i}}$ stands for the volume fraction for $\mathrm{i}$ component in the stationary phase. $\mathrm{V}_{\mathrm{i}}$ is the molar volume of component $i$ in the mixture.

On the contrary, assuming the Scott-Tompa approximation (Tompa, 1956), which describes a ternary system as a simple balance of the corresponding binary systems it is possible to calculate the surfactant-surfactant interaction parameter, $\chi_{23}$, by:

$$
\chi_{1(23)}^{\infty}=\phi_{2} \chi_{12}^{\infty}+\phi_{3} \chi_{13}^{\infty}-\phi_{2} \phi_{3} \chi_{23}\left(\frac{V_{1}}{V_{2}}\right)
$$

As it has been indicated by different authors, the polymer-polymer interaction parameter determined by IGC shows a clear dependence on the solvent used as a probe. In order to solve this problem, different methods have been proposed. The Farooque and Deshpande (Farooque, \& Deshpande, 1992) and the Huang (Huang, 2003a, 2003b) methodologies will be applied to retention data obtained from the use of surfactant anhidrous mixtures in order to carry out a comparative analysis of the behaviour of these methodologies in the determination of surfactant-surfactant interaction parameters.

Farooque and Deshpande (Farooque, \& Deshpande, 1992) methodology gives a reliable true interaction parameter after a rearrangement of Eq. (8):

$$
\frac{\left[\chi_{1(23)}^{\infty}-\chi_{13}^{\infty}\right]}{V_{1}}=\left[\frac{\phi_{2}\left(\chi_{12}^{\infty}-\chi_{13}^{\infty}\right)}{V_{1}}\right]-\phi_{2} \phi_{3}\left[\frac{\chi_{23}}{V_{2}}\right]
$$

A plot of the left side of this expression versus the first term of the right-hand side yields a lineal function from whose slope $\phi_{2}$ can be calculated and from the intercept $\chi_{23}$ can be obtained. The physical meaning of the slope was interpreted in terms of an effective average column composition that the solutes are probing.

Huang (Huang, 2003a, 2003b)et. al. have proposed an alternative rearrangement of Eq.( 8):

$$
\frac{\chi_{1(23)}^{\infty}}{V_{1}}=\left[\frac{\phi_{2} \chi_{12}^{\infty}+\phi_{3} \chi_{13}^{\infty}}{V_{1}}\right]-\phi_{2} \phi_{3}\left[\frac{\chi_{23}}{V_{2}}\right]
$$

A linear plot can be obtained from the left-hand side vs. first term of right-side of Eq.(10) allowing that the interaction parameter can be obtained.

In both methodologies, if the conditions given by Al-Saigh and Munk (Al-Saigh \& Munk, 1984) are obeyed, the surfactant-surfactant interaction parameter can be calculated through the specific retention volume without calculating the individual parameter.

The values of the surfactant-surfactant interaction parameters can be analyzed as $\chi_{23} / V_{2}$ or as $\chi_{23}$ when multiplied by $V_{2}$, or as the equivalent quantity $B_{23}=R T\left(\chi_{23} / V_{2}\right)$ (in J.cm $\left.{ }^{-3}\right)$ called energy density. 


\section{Results and discussion}

\subsection{Surfactants as stationary phases}

In this chapter both DSC and IGC were used to confirm the stationary phase stability with temperature. The phase transition temperatures were determined with DSC on pure surfactants between 293 and $523 \mathrm{~K}$. The same technique was also employed to analyze the thermal behaviour of both surfactants deposited over the solid support in a $10 \%(\mathrm{w} / \mathrm{w})$ percentage, approximately.

Chow and Martire (Chow \& Martire, 1971) compared IGC and DSC studies on two azoxy liquid crystals and reported no measurable adsorption effects from the interface above a film thickness of $100 \mathrm{~nm}$. Witkiewicz (Rayss, J. et al., 1980) reported surface orientation effects up to depth of $2 \mathrm{~nm}$, but in a later work reported constant specific retention volumes above a stationary phase loading of above 5\% (Marciniak \& Witkiewicz, 1981). Zhou et al. (Zhou, 1994) in the GC and IR study of liquid crystal deposited on different types of silica have shown that for a percentage under of $7 \%$ of the stationary phase loading, the $\ln \mathrm{Vg}$ vs $1 / \mathrm{T}$ plot did not show discontinuity. The loading used in this work was near of $10 \%$ on Chromosorb $\mathrm{W}$ in all the cases.

The retention diagram of $\ln \mathrm{Vg}$ vs $1 / \mathrm{T}$ for solute probes in DODAB and DDAB coated on Chromosorb W, NAW, 60/80, is shown in Figure 1 (Bardavid, et al., 2007). For both surfactants, specific retention volumes were obtained between $303 \mathrm{~K}$ and $423 \mathrm{~K}$. On heating the crystalline solid, the retention decreases until the crystalline solid-to-liquid crystal transition is reached. Then there is a large increase in retention, which once the system phase change finished, decreases with increasing temperature. For DDAB and DODAB changes in retention are observed at $343.1 \mathrm{~K}$ and $358.1 \mathrm{~K}$ respectively.
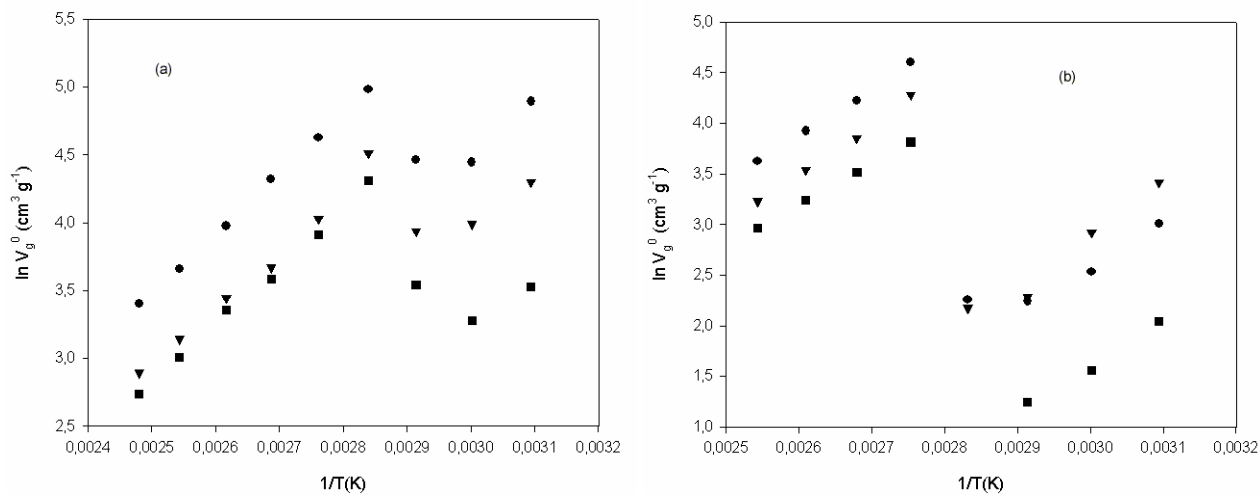

Fig. 1. The retention diagram for solute probes in DDAB (a) and DODAB (b) coated on Chromosorb W. Solutes: $(\bullet)$, toluene; $(\boldsymbol{\bullet})$, carbon tetrachloride; $(\boldsymbol{\nabla})$, n-octane.

DSC measurements of the phase transition temperature for DDAB y DODAB have been described in the literature (Schulz, et al., 1994, 1998). The experimental measurements for DDAB (Bardavid, et al., 2007), DSC analysis shows a temperature transition between the solid phase and liquid crystal mesophase through two peaks at $336.8 \mathrm{~K}$ and $349.2 \mathrm{~K}$. These values were coincident with those obtained in bibliography (Schulz, et al., 1994). The first peak 
corresponds to the melting of hydrocarbon tails of DDAB and that at $349.2 \mathrm{~K}$ corresponds to the melting of the DDAB polar heads bilayer giving an anhydrous lamellar liquid crystal which in some circumstances (i.e., when lamellae are parallel to the slide surface) appears as pseudo-isotropic. There is another phase transition at $445.9 \mathrm{~K}$ that could be the transition to isotropic liquid. DSC values in the literature have been informed up to $445.9 \mathrm{~K}$.

DSC analysis for pure DODAB shows a phase transition at $361.8 \mathrm{~K}$ (Bardavid, et al., 2007). According to the literature (Schulz, et al., 1994) this transition corresponds to the melting of DODAB crystals to a liquid which was named a pseudoisotropic liquid (Schulz, et al., 1998). We have not detected in our thermogram the hydrocarbon tails transition temperature, perhaps because both transitions (i.e., the melting of the polar and the apolar layer) occur at almost the same temperature giving an overlapping of their peaks; but we have detected another transition temperature at $439.3 \mathrm{~K}$ that we considered as the transition from mesophase to isotropic liquid. The transitions for DDAB and DODAB in literature (Schulz, et al., 1994, 1998) were studied up to smaller temperatures than ours. DDAB and DODAB supported on Chromosorb W NAW show a slight displacement toward smaller temperatures with respect to pure surfactants. There is previous information about discrepancies in the results when liquid and supported samples are analyzed by DSC, with lower values of transition temperature for the last ones (Shillcock \& Price, 2003).

The systems DPC and CPB, either pure or mixed, are lamellar mesophases at the working temperature (Laughlin, 1990). The obtained results trough DSC in pure surfactant samples for the change from crystal phase to liquid crystal phase is one peak at $343.1 \mathrm{~K}$ and others two peaks at $436.1 \mathrm{~K}$ and $513.1 \mathrm{~K}$ for DPC (Bardavid, et al., 2011).

In the case of CPB one peak is at $339.4 \mathrm{~K}$ and the other two at $421.7 \mathrm{~K}$ and $518.1 \mathrm{~K}$ ( Bardavid, et al., 2011). When the surfactants are deposited on chromatographic support (Chromosorb G, AW, 60/80) the values obtained through DSC for the phase changes are at

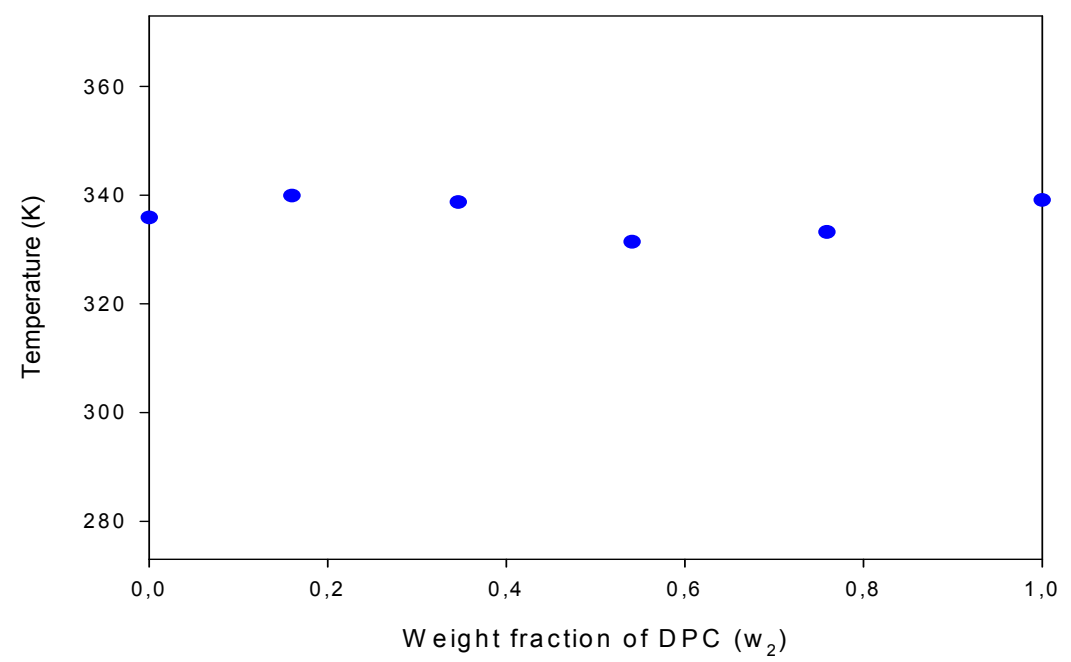

Fig. 2. Phase transition temperature for the surfactant mixtures DPC-CPB deposited on the solid support as function of the weight fraction of component 2 (DPC). 
$339.1 \mathrm{~K}$ for DPC and at $335.9 \mathrm{~K}$ for CPB. In Figure 2 we have included the values of phase transition temperature for the surfactant mixtures deposited on the solid support as function of the weight fraction of component 2 (DPC) ( Bardavid, et al., 2011).

When the studied system consists of DTAB and OTAB either pure or mixed, deposited on Chromosorb W, produced lamellar mesophases at work temperature (Laughlin, 1990). DSC experiments showed the phase changes from crystal to liquid crystal occurring at $372.5 \mathrm{~K}$ for DTAB and at $378.1 \mathrm{~K}$ for OTAB (Bardavid, et al., 2010). IGC measurements of the retentive behavior of n-octane and toluene between 338.1 and $423.1 \mathrm{~K}$ indicate (in the $\ln \mathrm{Vg}$ vs. 1/T plot) retention changes at $368.1 \mathrm{~K}$ for DTAB and $373.1 \mathrm{~K}$ for OTAB. The anhydrous crystal to lamellar phase transition in pure dodecyltrimethylammonium chloride (DTAC) occurs at about $356.1 \mathrm{~K}$ (Blackmore \& Tiddy, 1990). Taking into account the effect of changing the counterion, the agreement is good.

The DSC technique is very accurate in determining the pure component properties and the IGC results can be used as supplement to the DSC results in the case of surfactant deposited on solid support. The values of transition temperatures obtained by IGC are always lower than those obtained by DSC, and even more when the very start detection method is used to obtain the transition temperature by means of gas chromatography (Benabdelghani, et al., 2006; Nastasovic \& Onjia, 2008; Shillcock \& Price, 2003).

According to these results, it is possible to point out that both pure surfactants and their mixtures appear as a lamellar mesophase at the working temperature (388-403 K). Thus, we can infer that the probe solutes dissolve in a stationary phase formed by an ordered structure of lamellar mesophase.

\subsection{Interaction parameter in mixtures}

The systems studied, which are made up by cationic surfactants deposited on Chromosorb $\mathrm{W}$ or $\mathrm{G}$, being either pure or mixed, appear as lamellar mesophase at work temperature (Laughlin, 1990) and their temperatures of transition phases have been determined by DSC and IGC. In two systems we have used Chromosorb W, 60/80, with a charge close to $10 \%$ of stationary phase, and when Chromosorb G, 60/80 was used, the percentage of charge of stationary phase was close to $7 \%$. These values are considered to be adequate for this type of chromatographic support (Conder \& Young, 1978; Nastasovic \& Onjia, 2008). To ensure that the results were independent of sample size and flow rate and since measurements were being made at infinite dilution, the usual checks were made (Conder \& Young, 1978).

As shown by Etxabarren et al. (Etxabarren, et al., 2002), in polymeric materials the polymerprobe solute interaction parameters depend on the polymer molecular mass in intermediate concentration zones, and this dependence vanishes at very high concentration as in the case presented in IGC. These conclusions have lead us to analyze the behaviour in surfactant mixtures which present molecular mass that are much lower than those of the polymers with Tompa's approximation (Tompa, 1956) to ternary systems in Flory Huggins's theory.

As pointed out in the introduction, the measurements made in liquid state through IGC allow the determination of thermodynamic properties (Deshpande, et al., 1974), especially of interaction parameters that play an important role in determining the miscibility of 
mixtures. The behaviour of surfactant mixtures has been determined by IGC allowing the experimental determination of surfactant-surfactant interaction parameters in systems with different characteristics (Bardavid, et al., 2007, 2010, 2011).

Negative values of $B_{23}$ are indicative of attractive interactions and hence higher miscibility. On the contrary, positive values of $B_{23}$ would indicate repulsive interactions between the two polymers and they are related to immiscibility (Al-Saigh \& Munk, 1984; Benabdelghani, et al., 2006; Deshpande, et al., 1974; DiPaola-Baranyi \&. Degre, 1981; Etxeberria et al., 2000; Shi \& Screiber, 1991). From a theoretical point of view, this parameter should be constant with the concentration. Nevertheless, it has frequently been found that its value changes with concentration (Etxeberria, et al., 1994).

Through IGC (Bardavid, et al., 2007) we have studied the system DDAB (didodecyldimethyl ammonium bromide) and DODAB (dioctadecyldimethyl ammonium bromide), which are two twin tailed surfactants, the system DTAB (Dodecyltrimethyl ammonium bromide) and OTAB (Octadecyltrimethylammonium bromide) (Bardavid, et al., 2010) and the system DPC (Dodecylpyridinium chloride) and CPB (Hexadecylpyridinium bromide) (Bardavid, et al., 2011). The values of $B_{23}$ obtained in the former were positive in all the range of concentration and at all temperatures. They were also indicative of high inmiscibility and they coincided with the behaviour of these surfactant mixtures in aqueous solutions (Feitosa, et al., 2006). This is not surprising because the structure of anhydrous lamellar liquid crystals formed by melting the crystals must fulfill the same conditions that lamellar mesophases formed in aqueous solutions, i.e., polar headgroups must be in polar layers and the chains in apolar bilayers.

In the system DTAB and OTAB most of the values in $B_{23}$ are negative for each studied temperature. Negative values of $B_{23}$ suggest that the interaction between surfactants is more favourable as DTAB concentration increases. There are some precedents in aqueous solutions in which these surfactants form mixed micelles (Akisada, et al., 2007; Schulz, et al., 2006).

In the system DPC and $\mathrm{CPB}$ all the $\mathrm{B}_{23}$ values are positive in the range of concentration and temperature studied. These values are lower than the $B_{23}$ values obtained in the DDAB and DODAB system. To our knowledge, studies of mixtures DPC and CPB, neither pure nor aqueous solution, have not been carried out.

In this mixture of surfactants deposited on a solid support, an ordering can be expected due to the fact that the polar head would be directed to a solid surface. There is some indication that the pyridinium head group may interact specifically with surface sites, most likely by hydrogen bonding (Fuerstenau \& Jia, 2004). Thus it is expected that the repulsion between the counter ions and the $\pi$-electron cloud on the pyridinium ring together with lower charge on nitrogen atom is responsible for high $\alpha$-value of such surfactants ( $\alpha$ being the micelle ionization degree), higher than their trialkylammonium counter-parts (Bhat, et al., 2007). This would explain the difference in the behaviour in these systems.

As usual, in polymer mixtures increasing the temperature the interactions become weaker; thus the values of $\mathrm{B}_{23}$ become more positive at higher temperatures (Benabdelghani, et al., 2006). A similar behaviour can be observed in the systems with the surfactants studied. 


\subsection{Farooque-Deshpande and Huang methodology}

Farooque and Deshpande (Farooque, \& Deshpande, 1992) and Huang's (Huang, 2003a, $2003 \mathrm{~b})$ methodologies have been shown to be effective and reliable to determine the interaction parameter $\chi_{23}$ in polymers by IGC, since these parameters were questioned because of their dependence on the probe solutes used.

We have applied the thermodynamic relations determined by IGC for polymer mixtures to anhydrous surfactant mixtures and have proved that the results obtained show a behaviour that is coherent among the systems studied. Similarly, we have proved that the results are coherent with some results obtained in aqueous solutions of cationic surfactants. It's worth noting that the equations used in the measurement of $B_{23}$ would be only valid for miscible mixtures, although they have been applied successfully to several systems that show immiscibility (Du, et al., 1999; Zhikuan, \& Walsh, 1983). Benabdelghani et al. (Benabdelghani, et al., 2006) have carried out an analysis of both methodologies in a study of phase behaviour of poly(styrene-co-methacrylic acid)/poly(2,6-dimethyl-1,4-phenylene oxide) through IGC of polymer mixtures.

They have concluded that both methods show similar interaction parameter values and that both can be considered as reliable to determine the true polymer mixture parameters.

The possibility to count with experimental data in three binary systems of anhydrous surfactants, their molar volume and to devise a method to classify miscibility in mixtures has led us to apply both methodologies to surfactant mixtures. Besides, this allows us to prove if both methods can be used in these types of substances.

In Table 3 we have included the values obtained from the intercept, its errors and the correlation coefficients with the lineal fitting of the data applied to the equations (9 and 10) using both methodologies for the system DDAB - DODAB. This system presents positive values of $B_{23}$ that indicate the presence of immiscibility in this mixture.

Several observations can be made on the obtained values. First, the interception values in this system (DDAB - DODAB), are nearly equal for both methodologies. Using Huang's methodology the errors are the double or larger. The correlation coefficients of the lineal regression are excellent in Huang's methodologies in contrast to Farooque y Deshpande's (F-D) (Farooque, \& Deshpande, 1992) which are good.

These results are similar to those obtained from the comparison between both methods made by Benabdeghani et al. (Benabdelghani, et al., 2006) in the system Poly(styrene-comethacrylic acid) - Poly(2,6-dimethyl-1,4-phenylene oxide), which have led them to conclude that both methods are reliable to calculate interaction parameter values in polymer mixtures with miscible and immiscible regions.

In Table 4 we have included the system DPC - CPB, which also presents positive values of $\mathrm{B}_{23}$ that indicate the presence of immiscibility in this mixture, where the situation is different. In general, the intercept values are lower using Huang's method and errors are higher (five times or more) than those determined by F-D method. Something peculiar appears at a minor percentage of component 3 (CPB). At all temperatures the obtained intercept values are similar and the errors obtained by Huang are slightly higher. 


\begin{tabular}{|c|c|c|c|c|c|c|}
\hline $363.1 \mathrm{~K}$ & \multicolumn{3}{|c|}{$\mathrm{F}-\mathrm{D}$} & \multicolumn{3}{|l|}{ Huang } \\
\hline $\mathrm{w}_{2}(\mathrm{DDDAB})$ & ord.104 & $\pm \sigma .10^{5}$ & $r^{2}$ & ord.104 & $\pm \sigma .10^{5}$ & $r^{2}$ \\
\hline 0.1643 & 18.64 & 1.28 & 0.9779 & 18.91 & 3.40 & 0.9999 \\
\hline 0.3281 & 19.98 & 2.05 & 0.9902 & 19.61 & 2.51 & 0.9999 \\
\hline 0.5037 & 18.34 & 4.90 & 0.9796 & 17.30 & 6.15 & 0.9996 \\
\hline 0.7325 & 17.06 & 4.51 & 0.9926 & 15.04 & 3.63 & 0.9998 \\
\hline Average & & 3.18 & & & 3.92 & \\
\hline $373.1 \mathrm{~K}$ & \multicolumn{3}{|c|}{$F-D$} & \multicolumn{3}{|l|}{ Huang } \\
\hline $\mathrm{w}_{2}$ & ord.104 & $\pm \sigma .10^{5}$ & $r^{2}$ & ord.104 & $\pm \sigma .10^{5}$ & $r^{2}$ \\
\hline 0.1643 & 21.11 & 2.95 & 0.9260 & 21.34 & 5.16 & 0.9997 \\
\hline 0.3281 & 23.54 & 3.11 & 0.9812 & 23.41 & 5.10 & 0.9997 \\
\hline 0.5037 & 21.81 & 3.83 & 0.9900 & 20.57 & 6.31 & 0.9996 \\
\hline 0.7325 & 20.62 & 4.63 & 0.9931 & 19.40 & 6.05 & 0.9996 \\
\hline Average & & 3.63 & & & 5.65 & \\
\hline $383.1 \mathrm{~K}$ & \multicolumn{3}{|c|}{$F-D$} & \multicolumn{3}{|l|}{ Huang } \\
\hline $\mathrm{w}_{2}$ & ord.104 & $\pm \sigma .10^{5}$ & $r^{2}$ & ord.104 & $\pm \sigma .10^{5}$ & $r^{2}$ \\
\hline 0.1643 & 25.95 & 1.80 & 0.9538 & 27.17 & 7.16 & 0.9996 \\
\hline 0.3281 & 27.86 & 2.12 & 0.9908 & 28.30 & 5.14 & 0.9998 \\
\hline 0.5037 & 26.47 & 3.80 & 0.9912 & 25.27 & 7.68 & 0.9995 \\
\hline 0.7325 & 24.48 & 7.81 & 0.9801 & 25.68 & 13.69 & 0.9981 \\
\hline Average & & 3.88 & & & 8.42 & \\
\hline $393.1 \mathrm{~K}$ & \multicolumn{3}{|c|}{$F-D$} & \multicolumn{3}{|l|}{ Huang } \\
\hline $\mathrm{w}_{2}$ & ord.104 & $\pm \sigma .10^{5}$ & $r^{2}$ & ord.104 & $\pm \sigma .10^{5}$ & $r^{2}$ \\
\hline 0.1643 & 32.59 & 4.31 & 0.8580 & 35.00 & 8.24 & 0.9995 \\
\hline 0.3281 & 33.76 & 3.41 & 0.9835 & 35.32 & 5.09 & 0.9998 \\
\hline 0.5037 & 33.36 & 4.21 & 0.9906 & 34.60 & 7.04 & 0.9996 \\
\hline 0.7325 & 30.96 & 6.12 & 0.9910 & 33.34 & 10.61 & 0.9990 \\
\hline Average & & 4.51 & & & 7.74 & \\
\hline $403.1 \mathrm{~K}$ & \multicolumn{3}{|c|}{$F-D$} & \multicolumn{3}{|l|}{ Huang } \\
\hline $\mathrm{w}_{2}$ & ord.104 & $\pm \sigma .10^{5}$ & $r^{2}$ & ord.104 & $\pm \sigma .10^{5}$ & $r^{2}$ \\
\hline 0.1643 & 40.50 & 3.48 & 0.8936 & 42.28 & 12.64 & 0.9991 \\
\hline 0.3281 & 41.19 & 5.09 & 0.9684 & 42.45 & 12.18 & 0.9991 \\
\hline 0.5037 & 39.76 & 6.09 & 0.9847 & 40.44 & 13.24 & 0.9988 \\
\hline 0.7325 & 37.40 & 7.75 & 0.9886 & 39.43 & 18.72 & 0.9974 \\
\hline Average & & 5.60 & & & 14.19 & \\
\hline
\end{tabular}

Table 3. Intercepts (ord), standard deviations $(\sigma)$, and correlation coefficients $\left(\mathrm{r}^{2}\right)$ in the system DDDAB - DODAB. 


\begin{tabular}{|c|c|c|c|c|c|c|}
\hline $348.1 \mathrm{~K}$ & \multicolumn{3}{|c|}{$F-D$} & \multicolumn{3}{|l|}{ Huang } \\
\hline $\mathrm{w}_{2}(\mathrm{DPC})$ & ord.104 & $\pm \sigma .10^{5}$ & $r^{2}$ & ord.104 & $\pm \sigma .10^{5}$ & $\mathrm{r}^{2}$ \\
\hline 0.1598 & 9.41 & 3.46 & 0.9846 & 4.94 & 11.45 & 0.9990 \\
\hline 0.3461 & 8.48 & 3.84 & 0.9944 & 3.17 & 11.46 & 0.9990 \\
\hline 0.5409 & 8.66 & 4.85 & 0.9958 & 3.54 & 10.12 & 0.9990 \\
\hline 0.7590 & 12.07 & 3.81 & 0.9984 & 10.14 & 4.40 & 0.9999 \\
\hline Average & & 4.08 & & & 10.76 & \\
\hline $358.1 \mathrm{~K}$ & \multicolumn{3}{|c|}{ F - D } & \multicolumn{3}{|l|}{ Huang } \\
\hline $\mathrm{w}_{2}$ & ord.104 & $\pm \sigma .10^{5}$ & $r^{2}$ & ord.104 & $\pm \sigma .10^{5}$ & $r^{2}$ \\
\hline 0.1598 & 15.30 & 5.39 & 0.9557 & 12.34 & 15.39 & 0.9982 \\
\hline 0.3461 & 14.80 & 3.60 & 0.9950 & 8.76 & 12.38 & 0.9989 \\
\hline 0.5409 & 13.36 & 3.82 & 0.9975 & 7.14 & 11.42 & 0.9991 \\
\hline 0.7590 & 17.74 & 3.50 & 0.9986 & 16.50 & 3.87 & 0.9999 \\
\hline Average & & 4.08 & & & 10.76 & \\
\hline $368.1 \mathrm{~K}$ & \multicolumn{3}{|c|}{$F-D$} & \multicolumn{3}{|l|}{ Huang } \\
\hline $\mathrm{w}_{2}$ & ord.104 & $\pm \sigma .10^{5}$ & $r^{2}$ & ord.104 & $\pm \sigma .10^{5}$ & $r^{2}$ \\
\hline 0.1598 & 18.28 & 3.91 & 0.9846 & 10.56 & 23.39 & 0.9964 \\
\hline 0.3461 & 18.51 & 2.99 & 0.9952 & 10.23 & 17.84 & 0.9979 \\
\hline 0.5409 & 16.67 & 3.84 & 0.9976 & 7.39 & 16.37 & 0.9982 \\
\hline 0.7590 & 21.93 & 2.86 & 0.9991 & 19.57 & 3.07 & 0.9999 \\
\hline Average & & 3.40 & & & 15.17 & \\
\hline & \multicolumn{3}{|c|}{$F-D$} & \multicolumn{3}{|l|}{ Huang } \\
\hline $378.1 \mathrm{~K}$ & ord.104 & $\pm \sigma .10^{5}$ & $r^{2}$ & ord.104 & $\pm \sigma .10^{5}$ & $\mathrm{r}^{2}$ \\
\hline 0.1598 & 20.50 & 7.51 & 0.9676 & 7.33 & 47.29 & 0.9874 \\
\hline 0.3461 & 21.42 & 4.81 & 0.9942 & 7.53 & 35.96 & 0.9925 \\
\hline 0.5409 & 18.90 & 4.78 & 0.9974 & 2.65 & 32.48 & 0.9939 \\
\hline 0.7590 & 23.85 & 1.81 & 0.9997 & 17.53 & 8.27 & 0.9995 \\
\hline Average & & 4.73 & & & 31.00 & \\
\hline
\end{tabular}

Table 4. Intercepts (ord), standard deviations $(\sigma)$, and correlation coefficients $\left(\mathrm{r}^{2}\right)$ in the system DPC- CPB.

In Huang's method the correlation coefficients for all percentages and at all temperatures are greater than 0.999 and in the method $\mathrm{F}-\mathrm{D}$ the value of these coefficients is between 0.95 and 0.999 .

In Table 5, the values obtained from the intercept, their error and correlation coefficients from the lineal fitting of the data for the system DTAB - OTAB are included. This system presents a partial miscibility in accordance with the values of $B_{23}$ obtained by $F-D$, the intercept values determined by both methodologies present major differences between the systems studied; all the values determined by $\mathrm{F}$ - D are negative except for the first values at the last two temperatures. 


\begin{tabular}{|c|c|c|c|c|c|c|}
\hline $388.1 \mathrm{~K}$ & \multicolumn{3}{|c|}{ F - D } & \multicolumn{3}{|l|}{ Huang } \\
\hline $\mathrm{w}_{2}(\mathrm{DTAB})$ & ord.104 & $\pm \sigma .10^{5}$ & $r^{2}$ & ord.104 & $\pm \sigma .10^{5}$ & $r^{2}$ \\
\hline 0.1102 & -6.31 & 43.51 & 0.9763 & 12.45 & 81.23 & 0.9548 \\
\hline 0.3652 & -13.52 & 43.27 & 0.9940 & 0.45 & 80.88 & 0.9564 \\
\hline 0.5963 & -15.20 & 41.07 & 0.9745 & -2.81 & 74.23 & 0.9632 \\
\hline 0.8331 & -13.89 & 45.15 & 0.9523 & -1.72 & 80.22 & 0.9566 \\
\hline Average & & 43.25 & & & 79.14 & \\
\hline $393.1 \mathrm{~K}$ & \multicolumn{3}{|c|}{$F-D$} & \multicolumn{3}{|l|}{ Huang } \\
\hline $\mathrm{w}_{2}$ & ord. $10^{4}$ & $\pm \sigma .10^{5}$ & $r^{2}$ & ord.104 & $\pm \sigma .10^{5}$ & $r^{2}$ \\
\hline 0.1102 & -1.20 & 39.70 & 0.9731 & 18.84 & 80.74 & 0.9548 \\
\hline 0.3652 & -9.62 & 39.74 & 0.9948 & 5.79 & 79.42 & 0.9575 \\
\hline 0.5963 & -11.31 & 41.13 & 0.9732 & 2.66 & 82.05 & 0.9549 \\
\hline 0.8331 & -9.98 & 41.82 & 0.9632 & 3.31 & 81.04 & 0.9558 \\
\hline Average & & 40.60 & & & 80.81 & \\
\hline $398.1 \mathrm{~K}$ & \multicolumn{3}{|c|}{ F - D } & \multicolumn{3}{|l|}{ Huang } \\
\hline $\mathrm{w}_{2}$ & ord.104 & $\pm \sigma .10^{5}$ & $r^{2}$ & ord.104 & $\pm \sigma .10^{5}$ & $r^{2}$ \\
\hline 0.1102 & 2.44 & 36.96 & 0.9716 & 22.97 & 81.64 & 0.9536 \\
\hline 0.3652 & -5.77 & 36.54 & 0.9750 & 10.53 & 79.58 & 0.9573 \\
\hline 0.5963 & -7.87 & 38.10 & 0.9705 & 7.58 & 82.38 & 0.9544 \\
\hline 0.8331 & -5.97 & 38.54 & 0.9364 & 8.11 & 82.71 & 0.9545 \\
\hline Average & & 37.53 & & & 81.58 & \\
\hline & \multicolumn{3}{|c|}{$F-D$} & \multicolumn{3}{|l|}{ Huang } \\
\hline $403.1 \mathrm{~K}$ & ord.104 & $\pm \sigma .10^{5}$ & $r^{2}$ & ord.104 & $\pm \sigma .10^{5}$ & $r^{2}$ \\
\hline 0.1102 & 5.89 & 33.96 & 0.9674 & 26.53 & 82.02 & 0.9534 \\
\hline 0.3652 & -3.25 & 34.79 & 0.9913 & 14.29 & 82.77 & 0.9538 \\
\hline 0.5963 & -5.28 & 35.94 & 0.9414 & 10.89 & 86.20 & 0.9506 \\
\hline 0.8331 & -3.05 & 37.07 & 0.9579 & 12.12 & 88.26 & 0.9487 \\
\hline Average & & 35.44 & & & 84.81 & \\
\hline
\end{tabular}

Table 5. Intercepts (ord), standard deviations $(\sigma)$, and correlation coefficients $\left(\mathrm{r}^{2}\right)$ in the system DTAB-OTAB.

In Huang's methodology, the only negative intercept values correspond to those of the last two weight fractions at the first temperature, but in this methodology the values show incoherence at the different temperatures. The highest errors appear in Huang's method (close to the double) and the correlation coefficients are good and similar in both methodologies (0.94 -0.99 in F-D and 0.94-0.96 in Huang).

In all systems we can point out that the major errors correspond to Huang's methodology, with a good correlation of the lineal regression in this method. This behaviour is similar to that obtained by Benabdelghani et al. (Benabdelghani, et al., 2006) in polymers, and as 
pointed out by these authors, this could be due to the fact that the experimental points fitted in Huang's method are far from the intercept and its determination is subject to a major error. The enlargement of the values that correspond to the intercept in Huang's methodology leads to the duplication of errors and to results that are less numerically stable in relation to F-D methodology.

It is worth mentioning that besides the intrinsic errors of the chromatographic method in the determination of the parameter $\chi_{23} / \mathrm{V}_{2}$ (obtained from a delicate balance between a ternary system $\left(\chi_{1(2,3)}\right)$ and two binary systems $\left(\chi_{12}\right.$ and $\left.\left.\chi_{13}\right)\right)$, there would be experimental errors of the method as pointed out by Etxeberria et al. (Etxeberria et al., 2000). One way of reducing the uncertainty in the values of $B_{23}$ is an adequate selection of probe solvents. In this way, we have tried to cover all the possible chemical structures and polarities, avoiding the tests with similar retention among the retentive possibilities in this type of surfactant. We have included hydrocarbons in the probe solutes although they are not recommended for the experimental determination of polymer interaction parameters (Etxeberria et al., 2000).

In Table 2, we have included values of solution enthalpies obtained of the retention time data vs. $1 / \mathrm{T}$, their errors at a level of reliability of $95 \%$ and the differences between the values of solution enthalpies for each of the systems studied. In general terms we can point out that the system DDAB - DODAB presents the slightest differences between $\Delta \mathrm{H}^{\mathrm{o}}{ }_{\mathrm{s}}$, and the minor error among the systems studied. Besides, both stationary phases would show a major apolar character due to the major density of hydrocarbon chain. The other two systems present similar values of solution heat and the highest values in the component with a minor hydrocarbon chain.

We have calculated the average errors in the solution heat of the systems studied, which are also included in Table 2. Thus, we can observe that the system DDAB - DODAB presents a minor average error in the solution heat of $0.81 \%$, the system DPC - CPB is intermediate with an average value of $1.01 \%$ and the third system DTAB - OTAB presents a major value of $1.21 \%$. The third system presents the lower values of $\mathrm{V}_{\mathrm{g}}$ among the systems we studied and the major experimental errors in this retention parameter. The percentage values of the errors in the system DTAB - OTAB are very different from those calculated in the other systems following the method F-D, and there is a large difference in the errors obtained from a retention time correlation as a function of $1 / \mathrm{T}$.

We have observed that in the results determined in the three systems by Huang's methodology (Huang, 2003a, 2003b) the value of the slope shows that when the withdrawal from the unit is greater, the difference between the intercept values is bigger in both methodologies.

In Table 6 we have included the values obtained from the differences between the intercept values determined by both methods in the systems studied and the slope calculated by Huang's methodology for the first values of temperature.

As it can be seen in Table 6, the highest values of the differences between intercept values are visible when the deviation of the slope from the unit is major. We have plotted the values of the differences between the ordinate values in the method F-D (Farooque, \& Deshpande, 1992) and in Huang's methodology (Huang, 2003a, 2003b) as a function of the 
slope determined by Huang's method. Figure 3 shows that in the systems DDAB-DODAB and $\mathrm{DPC}-\mathrm{CPB}$, the dots rest on a straight line, with a major concentration of the values closeness to the unitary slope value. When the slope values are higher, the differences between both methods are greater.

\begin{tabular}{|c|c|c|c|c|}
\hline \multicolumn{5}{|c|}{ DDAB-DODAB system } \\
\hline $363.1 \mathrm{~K}$ & \multicolumn{2}{|c|}{ Ord.104 } & & \multirow[b]{2}{*}{ Huang slope } \\
\hline $\mathrm{w}_{2}$ & F-D & Huang & Difference & \\
\hline 0.1643 & 18.64 & 18.91 & -0.27 & 1.000 \\
\hline 0.3281 & 19.98 & 19.61 & 0.37 & 1.006 \\
\hline 0.5037 & 18.34 & 17.30 & 1.04 & 1.013 \\
\hline 0.7325 & 17.06 & 15.04 & 2.02 & 1.023 \\
\hline \multicolumn{5}{|c|}{ DPC-CPB system } \\
\hline $348.1 \mathrm{~K}$ & \multicolumn{2}{|c|}{ Ord.104 } & & \\
\hline $\mathrm{w}_{2}$ & F-D & Huang & Difference & Huang slope \\
\hline 0.1598 & 9.41 & 4.94 & 4.47 & 1.037 \\
\hline 0.3461 & 8.48 & 3.17 & 5.31 & 1.045 \\
\hline 0.5409 & 8.66 & 3.54 & 5.12 & 1.044 \\
\hline 0.7590 & 12.07 & 10.14 & 1.93 & 1.018 \\
\hline \multicolumn{5}{|c|}{ DTAB-OTAB system } \\
\hline $388.1 \mathrm{~K}$ & \multicolumn{2}{|c|}{ Ord.104 } & & \\
\hline $\mathrm{w}_{2}$ & F-D & Huang & Difference & Huang slope \\
\hline 0.1102 & -4.31 & 12.45 & -16.76 & 0.8908 \\
\hline 0.3652 & -3.52 & 0.45 & -13.97 & 0.8903 \\
\hline 0.5963 & -15.20 & -2.81 & -12.39 & 0.8795 \\
\hline 0.8331 & -13.89 & -1.72 & -12.17 & 0.8563 \\
\hline
\end{tabular}

Table 6. Differences of the values between the intercept values determinate by both methodologies and the slope calculated by Huang's methodology.

The dots corresponding to the system DTAB-OTAB, are in a part of the graph opposite to the values found in the other two systems. In this system, it can be observed the higher differences between the ordinate values, the major errors in both methodologies; the errors in Huang's method are twice as big as those found in F-D, the correlation coefficients are similar and the slopes in Huang's method are minor than the unit.

In general terms, we can point out that the F-D method is numerically more stable than Huang's methodology in these systems. This would be due to the algebraic treatment of the departure expression. The higher values of the correlation coefficient in the regression are the result from the scale expansion in Huang's methodology.

As a conclusion, in these systems the results of the comparison between the methodologies are in agreement with what Benabdelghani et al. (Benabdelghani, et al., 2006) said. We also found that when the value of withdrawal of the slope from the unit in Huang's method is higher, the values are less reliable and there are higher errors than in the method of F-D. 


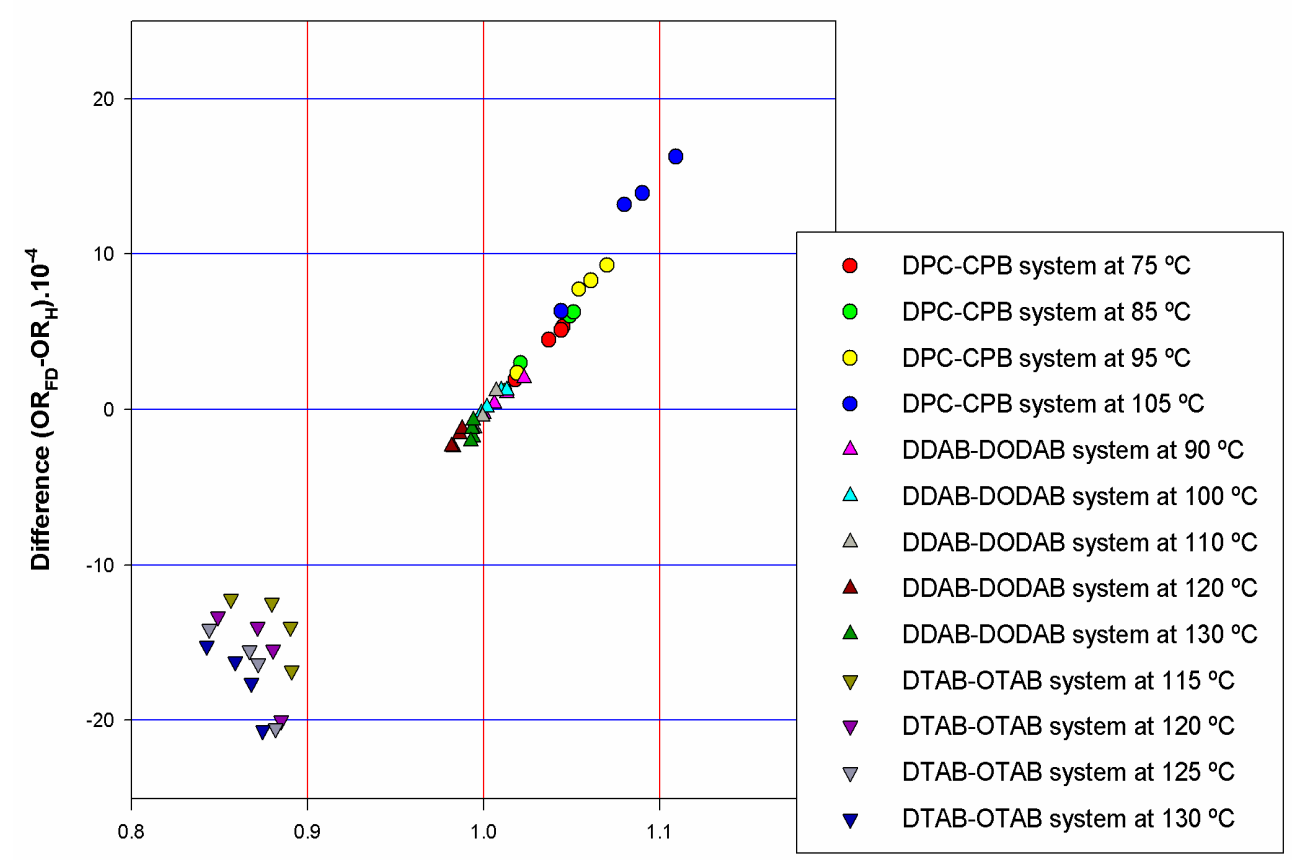

Slope in Huang Method

Fig. 3. Differences between the ordinate values in the method F-D and in Huang's methodology as a function of the slope determined by Huang's method.

\section{Conclusions}

The studied systems were different mixtures of anhydrous cationic surfactants, deposited on solid support, that has been used as stationary phases in IGC and the results were analyzed in term of mixtures miscibility.

The determination of the thermodynamic miscibility was realized by the values of surfactant-surfactant interaction parameters obtained by the same method used in polymeric materials.

The comparative use of two phenomenological methodologies allowed us to calculate the surfactant-surfactant interaction parameter in anhydrous cationic surfactant mixtures; the obtained results were similar to those obtained by Benabdelghaie et al. (Benabdelghani, et al., 2006) in polymeric materials. 
We also found that when the value of withdrawal of the slope from the unit in Huang's method is higher, the values are less reliable and there are major errors than in the method of F-D.

\section{Acknowledgments}

This work was sponsored by CIUNT (Consejo de Investigaciones de la Universidad Nacional de Tucumán) and partially by UNS. E.L.A. is a member of CONICET (Consejo Nacional de Investigaciones Científicas y Técnicas de la Republica Argentina).

\section{References}

Abe, A. \& Flory, P.J., (1978). Statistical thermodynamics of mixtures of rodlike particles. 2. Ternary systems. Macromolecules, 11, 1122-1126

Al-Saigh, Z. Y., \& Munk, P., (1984). Study of polymer-polymer interaction coefficients in polymer blends using Inverse Gas Chromatography. Macromolecules, 17, 803809

Akisada, H. , Kuwahara, J., Koga, A., Motoyama, H. \& Kaneda, H., (2007). Unusual behavior of CMC for binary mixtures of alkyltrimethylammonium bromides: Dependence on chain length difference. J. Colloid Interface Sci., 315, 678-684

Bardavid, S. M., Schulz, P. C. \& Arancibia, E. L., (2003). Solubility parameter determination of cationic surfactant by Inverse GC. Chromatographia, 57, 529-532

Bardavid, S. M., Schulz, P. C. \& Arancibia, E. L., (2007). IGC studies of binary cationic surfactant mixtures. J. Colloids Interface Sci., 316, 114-117

Bardavid, S. M., Schulz, P. C. \& Arancibia, E. L., (2010). Miscibility of anhydrous cationic surfactant mixtures. J. Mol. Liquids, 156, 165-170

Bardavid, S.M., Schulz, P.C. \& Arancibia, E.L., (2011). Interaction parameter of anhydrous cationic surfactant mixtures by IGC. Acepted in the J. Solution Chemistry (2011)

Benabdelghani, Z., Etxeberria, A., Djadoun, S., Uruin, J. J. \& Uriarte, C., (2006). The phase behaviour of poly(styrene-co-methacrylic acid)/poly(2,6-dimethyl-1,4-phenylene oxide) by Inverse Gas Chromatography. J. Chromatog. A, 1127, 237-245

Bhat, M. A., Dar, A. A., Amin, A., Rashid, P. I. \& Rather, G. M., (2007). Temperature dependence of transport and equilibrium properties of alkylpyridinium surfactants in aqueous solutions. J. Chem. Thermodyn., 39, 1500-1507

Blackmore, E. S. \& Tiddy, G. J. T. , (1990). Optical microscopy, multinuclear NMR $\left({ }^{2} \mathrm{H},{ }^{14} \mathrm{~N}\right.$ and $35 \mathrm{Cl}$ ) and $\mathrm{X}$-ray studies of dodecyl-and hexadecyl-trimethylammonium chloride/water mesophases. Liquid Crystals, 8, 131-151

Chow, L. C. \& Martire, D. E., (1971). Thermodynamics of solutions with liquid crystal solvents. III. Molecular interpretation of solubility in nematogenic solvents. J. Phys. Chem., 75, 2005-2015

Conder, J. R. \& Young, C. L., (1978) Physicochemical Measurement by Gas Chromatography, Wiley, New York

Deshpande, D. D., Patterson, D., Screiber, H. P. \& Su, C. S., (1974). Thermodynamic interactions in polymer Systems by Gas-Liquid-Chromatography. IV. 
Interactions between components in a mixed stationary phase. Macromolecules, 7, 530- 535.

DiPaola-Baranyi, G. \& Degre, P., (1981). Thermodynamic characterization of polystyrenepoly(butyl methacrylate) blends. Macromolecules, 14, 1456-1460.

Dreisbach, R. R., (1955) Advances Chemistry Series, publishing by A.C.S. Du, Q., Chen, W. \& Munk P., (1999). Inverse Gas Chromatography. 8. Apparent probe dependence of $\chi_{23}{ }^{\prime}$ for a poly(vinil chloride)-poly(tetramethylene glycol) blend. Macromolecules, 32, 1514-1518

El-Hibri, M. J., Cheng, W., \& Munk, P., (1988). Inverse Gas chromatography. 6.

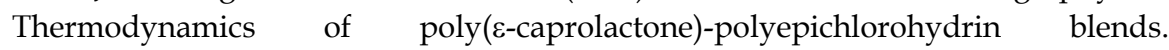
Macromolecules, 21, 3458-3463

Etxabarren, C., Iriarte, M., Uriarte, C., Etxeberria, A. \& Iruin, J. J., (2002). Polymer-solvent interaction parameters in polymer solutions at high polymer concentrations. $J$. Chromatogr. A, 969, 245-254

Etxeberria, A., Uriarte, C., Fernandez-Berridi, M.J. \& Uruin, J.J., (1994). Probing polymerpolymer interaction parameters in miscible blends by Inverse Gas Chromatography: Solvent effects. Macromolecules, 27, 1245-1248

Etxeberria, A., Iriarte, M., Uriarte, C., \& Iruin, J. J., (1995). Lattice Fluid Theory and Inverse Gas Chromatography in the analysis of polymer-polymer interactions. Macromolecules, 28, 7188-7195

Etxeberria, A., Etxabarren, C. \& Iruin, J. J., (2000). Comparison between static (sorption) and dynamic (IGC) methods in the determination of interaction parameters in polymer/polymer blends. Macromolecules, 33, 9115-9121

Farooque, A. M. \& Deshpande, D. D., (1992). Studies of polystyrene-polybutadiene blend system by inverse gas chromatography. Polymer, 33, 5005-5018.

Feitosa, E., Alves, F. R., Niemiec, A., Real Oliveira, M. E.C. D., Castanheira, E. M. S. \& Baptista, A. L. F., (2006). Cationic liposomes in mixed didodecyldimethylammonium bromide and dioctadecyldimethylammonium bromide aqueous dispersions studied by Differential Scanning Calorimetry, Nile Red Fluorescence, and Turbidity. Langmuir, 22, 3579-3585

Flory, P. J., (1953) Principles of Polymer Chemistry, Cornell University Press, Ithaca (NY)

Flory, P. J., (1956). Statistical thermodynamics of semi-flexible chain molecules. Proc. R. Soc., Lond. A, 234, 60-73

Flory, P. J. \& Abe, A., (1978). Statistical thermodynamics of mixtures of rodlike particles. 1. Theory for polydisperse systems. Macromolecules, 11, 1119-1122

Flory, P. J., (1984). Molecular theory of liquid crystals. Liquid Crystal Polymers I. Advances in Polymer Science, 59, 1-36

Fuerstenau, D. W. \& Jia, R., (2004). The adsorption of alkylpyridinium chlorides and their effect on the interfacial behavior of quartz. Colloids and Surfaces A: Physicochem. Eng. Aspects, 250, 223-231

Holland, P. M. \& Rubingh, D. N., (1990) In Cationic Surfactants; Holland, P. M. \& Rubingh, D. N. , Eds.; Surfactant Science Series; Marcel Dekker, New York, Vol. 37 
Huang, J. C., (2003a). Analysis of the thermodynamic compatibility of poly(vinyl chloride) and nitrile rubbers from Inverse Gas Chromatography. J. Appl. Polym. Sci., 89, 12421249

Huang, J. C., (2003b). Determination of polymer-polymer interaction parameters using Inverse Gas Chromatography. J. Appl. Polym. Sci., 90, 671-680

Huang, J. C., Coca, J. \& Langer, S. H., (2007). Liquid crystal solutions at infinite dilution: Solute phase transfer free energy and solubility parameter variations at phase conversion temperatures. Fluid Phase Equilib., 253, 42-47

Janini, G. M., Johnston, K. \& Zielinski, W. L. Jr., ( 1975). Use of a nematic liquid crystal for gas- liquid chromatographic separation of polyaromatic hydrocarbons. Anal. Chem., $47,670-674$

Janini, G. M., Manning, W. B., Zielinski, W. L. Jr.\& Muschik, M., (1980). Gas-liquid chromatographic separation of bile acids and steroids on a nematic liquid crystal. J. Chromatogr., 193, 444-450

Laughlin, R. G., (1990). Cationic Surfactants, Physical Chemistry, Ed. Rubingh, D. N. \& Holland, P. M., Marcel Dekker, New York

Laughlin, R., (1994). The aqueous phase behaviour of surfactants, Academic Press Inc., San Diego, CA

Lezcano, E. G., Prolongo, M. G. \& Salom Coil, C., (1995). Characterization of the interactions in the poly(4-hydroxystyrene)/poly(s-caprolactone) system by Inverse Gas Chromatography. Polymer, 36, 565-573

Marciniak, W. \& Witkiewicz, Z., (1981). Effect of the amount of liquid crystal and type of support on some properties of the liquid crystalline stationary phase-support system. J. Chromatogr. , 207, 333-343

Marquartd, D. W., (1963). An Algorithm for Least-Squares Estimation of Nonlinear Parameters. SIAM Journal on Applied Mathematics 11 (2) 431-441

Martire, D. E., Blasco, P. A., Carone, P. E., Chow, L. C.\& Vicini, H., (1968). Thermodynamics of solutions with liquid-crystal solvents. I. A Gas-Liquid Chromatographic study of cholesteryl myristate. J. Phys. Chem., 72, 3489-3495

Nastasovic, A. B. \& Onjia, A. E., (2008). Determination of glass temperature of polymers by Inverse Gas Chromatography. J. Chromatog. A, 1195, 1-15

Patterson, D., Tewari, Y.B. , Schreiber, H.B. \& Guillet, J.E., (1971). Application of Gas-Liquid Chromatography to the thermodynamics of Polymer Solutions. Macromolecules , 4, 356-359

Price, G. J., Hickling, S. J. \& Shillcock, I. M., (2002). Applications of Inverse gas Chromatography in the study of liquid crystalline stationary phases. J. Chormatogr. A, 969, 193-205

Prolongo, M. G., Masegosa, R. M. \& Horta, A., (1989). Polymer-polymer interaction parameter in the presence of a solvent. Macromolecules, 22 4346-4351

Proverbio, Z. E., Bardavid, S. M., Arancibia, E. L. \& Schulz, P. C., (2003). Hydrophilelipophile balance and solubility parameter of cationic surfactants. Colloids and Surf. A, Physicochem. Eng. Aspects, 214, 167-171 
Rayss, J., Witkiewicz, Z. , Waksmundzki, A. \& Dabrowski, R., (1980). Effect of the support surface on the structure of the film of liquid crystalline stationary phase. $J$. Chromatgr. A., 188, 107-113

Reid, R. C., Prausnitz, J. M. \& Poling, B. E., (1986). The properties of Gases and Liquids, 4th Ed., McGraw-Hill, New York

Riddick, A. R., Bunger, W. B. \& Sakano, T. K., (1986). Organic Solvents. Techniques of Chemistry, $4^{\text {th }}$ Ed., Wiley-Interscience, New York

Romannsky, M. \& Guillet, J. E., ( 1994). The use of Inverse Gas Chromatography to study liquid crystalline polymers. Polymer, 35, 584-589

Romannsky, M. , Smith, P. F., Guillet, J. E. \& Griffin, A. C., (1994). Solvent interactions with an insoluble liquid-crystalline polyester. Macromolecules, 27, 6297-6300

Schaefer, C. R. de, Ruiz Holgado, M. E. F. de \& Arancibia, E. L., (2008). Effective solubility parameters of sucrose monoester surfactants obtained by Inverse Gas Chromatography. Fluid Phase Equilib., 272, 53-59

Shi, Z. H. \& Screiber, H. P., (1991). On the application of Inverse Gas Chromatography to interactions in mixed stationary phases. Macromolecules, 24, 3522-3527

Shillcock, L. M. \& Price, G. J. , (2003). Inverse Gas Chromatography study of poly(dimethyl siloxane)-liquid crystal mixtures. Polymer, 44, 1027-1034

Shillcock, L. M. \& Price, G. J. , (2004). Interactions of solvents with low molar mass and side chain polymer Liquid Crystals measured by Inverse Gas Chromatography. J. Phys. Chem. B, 108, 16405- 16414

Schulz, P. C. , Puig, J. E. , Barreiro, G. \& Torres, L. A. ( 1994) . Thermal transitions in surfactant- based lyotropic liquid crystals. Thermochimica Acta 231, 239-256

Schulz, P.C., Abrameto, M., Puig, J.E., Soltero-Martínez, F.A. \& González-Alvarez, A., (1996). Phase Behavior of the Systems n-Decanephosphonic Acid - Water and nDodecanephosphonic Acid- Water. Langmuir, 12, 3082-3088

Schulz, P. C. , Rodriguez, J. L., Soltero-Martinez, A. Puig, J. E. \& Proverbio, Z. E., (1998). Phase behaviour of the dioctadecyldimethylammonium bromide-water system. $J$. Thermal Anal., 51, 49-62

Schulz, P. C., Rodríguez, J. L., Minardi, R. M., Sierra, M. B. \& Morini, M. A., (2006). Are the mixtures of homologous surfactants ideal? J. Colloid $\mathcal{E}$ Interface Sci., 303, 264271

Tompa, H., (1956). Polymer Solutions, Butterworths, London Varade, D., Aramaki, K. \& Stubenrauch, C., (2008). Phase diagrams of water- alkyltrimethylammonium bromide systems. Colloids Surf. A: Physicochem. Eng. Aspects, 315, 205-209

Voelkel, A., Strzemiecka, B., Adamska, K. \& Milczewska, K., (2009). Inverse Gas Chromatography as a source of physicochemical data. J. Chromatogr. A, 1216, 15511566

Zhao, L. \& Choi, P., (2001). Determination of solvent-independent polymer-polymer interaction parameter by an improved Inverse Gas Chromatographic approach. Polymer, 42, 1075-1081

Zhikuan, C. \& Walsh, D. J., (1983). Inverse Gas Chromatography for the study of one phase and two phase polymer mixtures. Eur. Polym. J., 19, 519- 524 
Zhou, Y. W. , Jaroniec, M., Hann, G. L. \& Gilpin, R. K., (1994). Gas Chromatographic and Infrared studies of 4'-cyano-4-biphenyl 4-(4-pentenyloxy)benzoate coated on porous silica. Anal. Chem., 66, 1454- 1458 


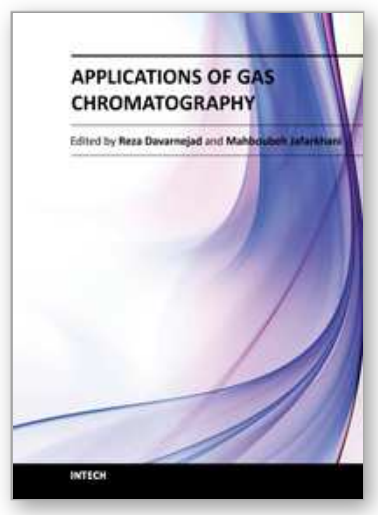

\author{
Applications of Gas Chromatography \\ Edited by Dr. Reza Davarnejad
}

ISBN 978-953-51-0260-1

Hard cover, 132 pages

Publisher InTech

Published online 07, March, 2012

Published in print edition March, 2012

This valuable book aims to provide a connection between various chromatography techniques and different processes. Authors applied these techniques in supercritical technology, medical, environmental, physique and chemical processes. Most of them prepared mathematical support (such as correlation) for their original results obtained from the chromatography techniques. Since chromatography techniques (such as GC, HPLC \& etc) are separating and analyzing methods, this chapters will help other researchers and young scientists to choose a suitable chromatography technique. Furthermore, this book illustrates the newest challenges in this area.

\title{
How to reference
}

In order to correctly reference this scholarly work, feel free to copy and paste the following:

Eleuterio Luis Arancibia, Pablo C. Schulz and Susana M. Bardavid (2012). Interaction Parameters of Surfactant Mixtures by Inverse Gas Chromatography, Applications of Gas Chromatography, Dr. Reza Davarnejad (Ed.), ISBN: 978-953-51-0260-1, InTech, Available from:

http://www.intechopen.com/books/applications-of-gas-chromatography/interaction-parameters-of-thesurfactant-mixtures-by-igc-

\section{INTECH}

open science | open minds

\section{InTech Europe}

University Campus STeP Ri

Slavka Krautzeka 83/A

51000 Rijeka, Croatia

Phone: +385 (51) 770447

Fax: +385 (51) 686166

www.intechopen.com

\section{InTech China}

Unit 405, Office Block, Hotel Equatorial Shanghai

No.65, Yan An Road (West), Shanghai, 200040, China

中国上海市延安西路65号上海国际贵都大饭店办公楼 405 单元

Phone: +86-21-62489820

Fax: +86-21-62489821 
(C) 2012 The Author(s). Licensee IntechOpen. This is an open access article distributed under the terms of the Creative Commons Attribution 3.0 License, which permits unrestricted use, distribution, and reproduction in any medium, provided the original work is properly cited. 